\title{
Ciência sem Fronteiras na formação profissional: percepções de estudantes de Odontologia da UFSM
}

\author{
Sílvia Ataide Pithan*; Marília Forgearini Nunes**; Luiza Chagas Pires*** \\ * Professora Adjunta do Curso de Odontologia da Universidade \\ Federal de Santa Maria \\ * Professora Adjunta da Faculdade de Educação da \\ Universidade Federal do Rio Grande do Sul \\ *** Cirurgiã-dentista, Universidade Federal de Santa Maria
}

Recebido em 06/03/2017. Aprovado em 07/09/2017.

\begin{abstract}
RESUMO
O objetivo deste trabalho foi avaliar a percepção de estudantes sobre o programa Ciência sem Fronteiras $(\mathrm{CsF})$ no curso de Odontologia da Universidade Federal de Santa Maria. Foi realizada pesquisa de caráter qualitativo, utilizando entrevista semiestruturada com acadêmicos que participaram do programa CsF. A entrevista foi gravada em áudio, transcrita e, após, procedeu-se a análise dos dados. A partir das entrevistas foram elaboradas seis categorias para análise: Língua estrangeira: fator motivacional e fator de dificuldade; Amadurecimento pessoal: uma expectativa concretizada; Falta de planejamento na criação do programa; Diferenças de metodologia do ensino superior; Impacto do Ciência sem Fronteiras na formação profissional e Contribuições do Ciência sem Fronteiras para a instituição e para o país. Conclui-se que os acadêmicos de Odontologia que participaram do programa perceberam mais impactos positivos na sua vida pessoal, ficando a formação profissional em segundo plano.

Descritores: Educação em Odontologia. Intercâmbio Educacional Internacional. Educação Superior.
\end{abstract}

\section{INTRODUÇÃO}

A internacionalização e mobilidade acadêmica nos mais diversos níveis da produção do conhecimento brasileiro é reconhecidamente relevante para o país, no cenário mundial atual ${ }^{1}$, pois oferece um leque de oportunidades para a expansão dos conhecimentos científicos e visões de mundo, proporcionando ao acadêmico uma visão ampla, reflexiva e crítica acerca das questões sociais, políticas, econômicas, pessoais e profisisonais ${ }^{2}$. Atento para essa necessidade, o governo brasileiro criou, em 2011, o programa Ciência sem Fronteiras (CsF) com o objetivo de promover a consolidação, expansão e internacionalização da ciência e tecnologia, da inovação e da competitividade brasileira por meio do intercâmbio e da mobilidade internacional ${ }^{3}$. Trata-se de um ambicioso programa de 
internacionalização da produção de conhecimento brasileira, que usa como instrumento central a mobilidade de profissionais $\mathrm{e}$ pesquisadores em formação ou formados ${ }^{4}$, sendo a primeira política pública que focou na internacionalização da educação superior no Brasil e é uma das mais significativas iniciativas de mobilidade internacional do mundo ${ }^{5}$.

O CsF previa a concessão de 101 mil bolsas de estudo em quatro anos para alunos de graduação e pós-graduação em universidades ao redor do mundo, sendo que 64.000 estariam destinadas à graduação sanduíche ${ }^{3}$. Dados de avaliação do programa demonstraram que o número total de bolsas distribuídas pelo $\mathrm{CsF}$ para graduação foi de 78.000 ao invés das 64.000 previstas inicialmente. Essa mudança foi justificada em função da demanda ${ }^{6}$.

Embora ainda seja cedo para estimar o impacto do programa nas questões tecnológicas e de inovação no Brasil, ou mesmo para avaliar a contribuição do CsF na internacionalização das universidades brasileiras, os resultados iniciais são encorajadores. No entanto, finalizada a primeira fase do programa, percebeu-se a necessidade de muitas modificações, como promover maior participação de estudantes de pós-graduação; enviar os estudantes de graduação para um número menor de instituições pré-definidas e aumentar a participação da instituição de origem do acadêmico; distribuir os estudantes em mais países e promover o intercâmbio para aumentar o número de estudantes estrangeiros no Brasil; excluir o treinamento em língua estrangeira no exterior; incluir outras áreas de conhecimento; garantir que os créditos cursados no exterior sejam aproveitados na volta ao Brasil; aumentar o financiamento do setor privado para as bolsas; assim como desenvolver mecanismos para consolidar o conhecimento obtido nesses programas na volta ao Brasil ${ }^{7}$.
A avaliação do ponto de vista dos acadêmicos também é importante uma vez que pouco se sabe sobre os resultados do programa CsF com alunos de graduação. Sendo assim, o objetivo desse trabalho foi avaliar a percepção de estudantes sobre o programa no curso de Odontologia da Universidade Federal de Santa Maria (UFSM). Também objetivou-se avaliar as principais dificuldades vivenciadas pelos acadêmicos, relatar suas experiências e avaliar o impacto na formação profissional desses estudantes.

\section{METODOLOGIA}

A pesquisa utilizou abordagem qualitativa de caráter descritivo e exploratório. O estudo foi realizado com alunos da graduação de Odontologia da UFSM que participaram do programa CsF desenvolvido pelo governo federal e que já haviam retornado para as atividades regulares, ou que tivessem concluído o curso. Os acadêmicos participaram do programa entre os anos de 2012 e 2015, sendo que todos foram convidados a participar.

Entre julho e outubro de 2015, foram feitas entrevistas semiestruturadas com questões abertas aos estudantes. As entrevistas foram realizadas por um único entrevistador, gravadas e transcritas. Os tópicos da entrevista tratavam de questões relacionadas ao conhecimento do programa; como se deu a escolha pela universidade de destino; como a língua estrangeira influenciou no processo; as vantagens e desvantagens de ter participado do programa; como foram as vivências pessoais e acadêmicas na universidade de destino; e as possíveis contribuições do $\mathrm{CsF}$ para a universidade de origem, para o país e para a formação profissional.

Foi feita análise de conteúdo temática seguindo modelo sugerido por Minayo ${ }^{8}$. O estudo está de acordo com a legislação vigente 
que rege pesquisa envolvendo seres humanos Resolução 466/2012, sendo submetido à apreciação e aprovado pelo Comitê de Ética em Pesquisa da instituição (CAAE 46850015.3. 0000.5346). Todos os participantes assinaram um Termo de Consentimento Livre e Esclarecido (TCLE) antes que qualquer entrevista fosse iniciada. Foi garantido sigilo sobre qualquer dado que pudesse identificar os participantes.

\section{RESULTADOS E DISCUSSÃO}

Dos 14 alunos do Curso de Odontologia que participaram do programa $\mathrm{CsF}$ e já finalizaram o mesmo, 13 participaram da pesquisa.

A partir da leitura das entrevistas foram elaboradas categorias para análise e interpretação do material, sendo elas Língua estrangeira: fator motivacional e fator de dificuldade; Amadurecimento pessoal: uma expectativa concretizada; Falta de planejamento na criação do programa; Diferenças de metodologia do ensino superior; Impacto de $\mathrm{CsF}$ na formação profissional e Contribuições do $\mathrm{CsF}$ para a instituição e para o país.

\section{Língua estrangeira: fator motivacional e fator de dificuldade}

Tomando como marco inicial as motivações que levaram os estudantes a participar do programa CsF, percebeu-se que o conhecimento de uma outra língua se destacou. $\mathrm{O}$ desejo de aprender uma língua estrangeira (LE) foi citado até mesmo como o motivo da escolha do país e/ou universidade:

"Eu escolhi a língua que eu queria e não a universidade." (Estudante 1)

"Eu acho que a questão da língua, porque eu estava fazendo inglês [...] $e$ não estava vendo resultado. Eu queria muito aprender uma outra língua. Não dei tanta atenção pra a questão acadêmica." (Estudante 2)

Essa importância conferida à língua com a qual se teria contato e, principalmente, a oportunidade de aprendê-la revela questões sociais, econômicas e políticas associadas ao mundo habitado pelos acadêmicos. A evolução dos meios de transporte e meios de comunicação encurtou a distância entre os homens e o conhecimento de uma LE, especialmente do inglês, permitindo que essa comunicação sem fronteiras aconteça $\mathrm{a}^{9,10}$.

Nas entrevistas, a proficiência em uma LE foi citada por diferentes perspectivas, por vezes paradoxais: como fator motivacional e, ao mesmo tempo, como uma barreira na seleção, como um fator determinante na escolha do país e como uma dificuldade durante a realização do intercâmbio. O problema da falta de fluência em um segundo idioma, mas ao mesmo tempo a oportunidade de alcança-la a partir do CsF revela o modo com que a LE foi fator relevante na experiência, como exemplificado pela fala de alguns entrevistados:

"Eu fui sem o inglês. Talvez se eu já soubesse inglês, teria optado por outro país, por outra universidade, uma universidade que desse mais abertura para a Odontologia." (Estudante 3)

Outros estudantes referem-se a dificuldade de comunicação:

"Fazer uma aula e se comunicar em uma língua que não é a tua?! Tu pensa na tua língua mãe e tem que falar em outra língua. É bem complicado. "(Estudante 4)

Pesquisa realizada entre 2009 e 2011 comprovou que os brasileiros falam mal inglês. O Brasil ficou em $46^{\circ}$ lugar do total de 54 nações pesquisadas no que se refere ao domínio da língua inglesa ${ }^{11}$. Isso reforça a necessidade de políticas públicas de capacitação em língua estrangeira. Visto a dificuldade para encontrar alunos aptos a participar do programa $\mathrm{CsF}$, o 
Ministério da Educação (MEC) por intermédio da Secretaria de Educação Superior (SESu) em conjunto com a Coordenação de Aperfeiçoamento de Pessoal de Nível Superior (CAPES), criou o programa Idiomas sem Fronteiras (IsF) com o objetivo de incentivar o aprendizado de línguas, além de propiciar mudança abrangente e estruturante no ensino de idiomas estrangeiros nas universidades do país $^{12,13}$, pois constatou-se a deficiência no conhecimento da $\mathrm{LE}^{1}$. Um exemplo disso é o grande número de estudantes que optaram por universidades lusitanas ${ }^{14}$ e o baixo número de acadêmicos aprovados nas chamadas para o Reino Unido (apenas 1,8 mil bolsas das 4 mil ofertadas foram preenchidas $)^{15}$.

Outras medidas adotadas para aumentar as possibilidades de participação foram a diminuição no nível de exigência no conhecimento de LE e a implantação da possibilidade de custear um estágio linguístico no país de destino. Ambas as medidas receberam várias críticas, uma vez que dado o objetivo do programa, o conhecimento de LE deveria ser um pressuposto ${ }^{16}$.

\section{Amadurecimento pessoal: uma expectativa concretizada}

Além da LE, a experiência pessoal apareceu na maior parte das entrevistas como uma motivação e como uma consequência.

Sair da zona de conforto da faculdade e conhecer coisas diferentes (Estudante 5).

[...] foi mais pela experiência não tanto pelo profissional (Estudante 6). [...] um intercâmbio com um adicional que os outros intercâmbios normais, que tem só $o$ inglês (Estudante 7). [... $\quad$ a possibilidade de estudar numa universidade que tem tecnologia de ponta, enfim outro país (Estudante 1).

$O$ processo de internacionalização das Instituição de Ensino Superior (IES) brasileiras se iniciou com programas de mobilidade internacional apoiadas por órgãos governamentais que acreditavam que, apesar das dificuldades, o desenvolvimento profissional e pessoal dos estudantes poderia ser alcançado $^{17}$. Os intercâmbios representam uma troca de informações, crenças, culturas e conhecimentos ${ }^{18}$ que podem levar ao crescimento e fortalecimento emocional $^{2}$. Esses objetivos e possibilidades manifestaram-se em muitas das falas dos entrevistados, uma vez que o programa $\mathrm{CsF}$, para muitos, foi uma aquisição de valores culturais e sociais através de uma experiência pessoal intensa onde os entrevistados relataram aprender, por meio do contato com culturas diferentes, a conviver com pessoas diferentes. Foram unânimes ao relatar sobre o amadurecimento pessoal em virtude de terem "que se virar sozinhos" em um país diferente e isso poderia ser aplicado na vivência profissional. Este amadurecimento pode ter se iniciado no período prévio ao intercâmbio quando o aluno tem que se envolver com burocracias como passaporte e visto, e alcançado sua plenitude durante a realização do mesmo quando é necessária a adaptação à cultura e às questões legais do país de destino.

Os entrevistados declararam que este amadurecimento pessoal os auxiliou, ao retornarem ao Brasil, na relação com os pacientes e no enfrentamento de desafios que antes eles julgavam difíceis de serem superados.

"Eu amadureci muito, hoje eu percebo que até a maneira como eu vou abordar o paciente é completamente diferente da maneira que eu abordava antes do Ciência sem Fronteira, eu consigo lidar mais com a situação" (Estudante 8).

"A oportunidade de ter ido pra lá e de ter vivido isso tudo, fez com que eu perdesse um pouquinho de medo de fazer as coisas [...] me fez criar uma confiança em mim 
pra fazer algumas coisas" (Estudante 9).

"O crescimento pessoal que nós temos é muito grande. Vamos com uma cabeça e voltamos com outra totalmente diferente. Uma cabeça super aberta, disposta a novos desafios" (Estudante 10).

$\mathrm{O}$ reconhecimento desse crescimento pessoal não é novidade. Embora o programa $\mathrm{CsF}$ seja recente, a mobilidade acadêmica já era vivenciada de outras maneiras. Segundo Oliveira e Pagliuca ${ }^{19}$, as vantagens dos intercâmbios vão além do aprendizado e se manifestam também no desenvolvimento psicológico, autoconfiança, amadurecimento, independência e capacidade de relacionar-se e sentir-se 'um cidadão do mundo'.

Além disso, a experiência internacional pode ser um componente importante para a análise dos sistemas nacionais de educação, das estratégias familiares de diferenciação no mercado da educação superior e na formação de setores profissionais. Por isso é importante acompanhar os sujeitos que participaram dessa experiência considerando o peso que a circulação de pessoas e saberes alcançou, a contribuição que esse processo tem trazido para os grupos profissionais e as inovações culturais decorrentes desse investimento de recursos públicos ${ }^{20}$.

\section{Falta de planejamento na criação do programa}

Observou-se a partir das entrevistas uma falta de organização do programa no sentido de fornecer apoio durante a escolha das universidades e falta de planejamento para disponibilizar universidades dentro da área de atuação do aluno. Os critérios acadêmicos acabaram, muitas vezes, relegados à um segundo plano. Essas lacunas podem ser percebidas em relatos dos acadêmicos:

"Existem universidades que não tem nenhum critério na seleção dos alunos. Tu te inscreve e a universidade manda... por isso que acabam acontecendo os turismos sem fronteiras..." (Estudante 3).

Percebe-se por essa fala que existe, entre os acadêmicos, a ideia de oportunidade de turismo a partir do programa, em função da falta de critério na seleção, tanto da universidade de destino, quanto dos acadêmicos participantes do programa.

O contato prévio com as instituições internacionais também recebeu críticas por parte dos estudantes.

"[...] o programa foi criado de cima para baixo. Criaram o programa, distribuíram as bolsas e depois foram falar com as universidades estrangeiras [...]" (Estudante 7). "Eu não escolhi a minha universidade, eu fui mandada aleatoriamente pra lá" (Estudante 11).

Os problemas apontados pelos intercambistas não passaram despercebidos pelos responsáveis pelo programa $\mathrm{CsF}$, que durante a $67^{\mathrm{a}}$ reunião anual da Sociedade Brasileira para o Progresso da Ciência (SBPC) apresentaram dados referentes ao programa. Um dos representantes do $\mathrm{CNPq}$ e um dos responsáveis pelo CsF afirmou que "o programa foi feito na marretada". Continua dizendo que na primeira fase, as agências sofreram para implantar o programa pois não tinham experiência de lidar com bolsistas de graduação no exterior ${ }^{21}$.

Percebe-se ainda a partir da análise das entrevistas que, devido a legislação de alguns dos países de destino exigirem uma etapa prévia ao ingresso nos cursos da área de saúde, muitos não puderam estudar disciplinas referentes a sua área $^{2}$.

"Na escolha da Universidade eu procurei o que tinha de mais similar com a Odontologia. Fui para onde era mais parecido". (Estudante 10)

"Justamente por ser um programa relacionado à universidade, o que 
esperava era pelo menos conhecer como funcionava a Odontologia no país que eu fui. Que a universidade desse uma abertura para presenciar as aulas, porque tinha o meu curso na universidade, tinha Odontologia, mas eles foram muito fechados a ponto de não poder fazer nem matéria teórica ligada a Odontologia. " (Estudante 3).

$\mathrm{O}$ aproveitamento das disciplinas também foi discutido durante a apresentação dos dados referentes ao $\mathrm{CsF}$ e a dificuldade vivenciada pelos acadêmicos do curso de Odontologia também foi percebida em outras áreas uma vez que $24 \%$ das disciplinas cursadas por participantes do programa não foram aproveitadas e outras $8 \%$ foram parcialmente aproveitadas nos seus respectivos cursos no Brasil ${ }^{7,21}$.

Sendo assim, cabe aos gestores do programa CsF a fiscalização e seleção de instituições que possam realmente contribuir para a qualificação profissional dos acadêmicos e que o programa cumpra com os seus objetivos de novas experiências profissionais voltadas para a qualidade em áreas estratégicas para o Brasil.

É importante esclarecer que a internacionalização do ensino superior não ocorre de maneira homogênea ${ }^{22}$, podendo ocorrer de forma ativa ou passiva. A internacionalização ativa está limitada a poucos países, sendo aqueles centrais e que possuem políticas de Estado voltadas para a atração e acolhimento de acadêmicos, a oferta de serviços educacionais no exterior envolvendo a mobilidade de experts em áreas de interesse estratégico, a exportação de programas e instalação de instituições ou campi no exterior. Já a internacionalização passiva ocorre nos países periféricos que acabam participando como fornecedores de estudantes ${ }^{23}$. Os Estados Unidos podem ser tomados como exemplo para que se entenda a internacionalização ativa. Esse país é o principal território hospedeiro de estudantes internacionais do mundo e, se considerados os sete países com maior capacidade de atração de estudantes (Estados Unidos, Reino Unido, Alemanha, França, Austrália, Canadá e Japão) constata-se a coincidência entre capacidade de captação de estudantes, pujança acadêmica, poder político e econômico. Destaca-se ainda que estes países são responsáveis por 2/3 da matrícula mundial dos estudantes em circulação ${ }^{24}$.

Essas instituições de ensino superior no mundo se utilizam da internacionalização do estudo como produto de venda onde alunos, que procuram em universidades estrangeiras uma experiência acadêmica que enriqueça seus currículos e lhes dêem uma experiência pessoal mais intensa, aceitam pagar as taxas impostas pela universidade de destino ${ }^{25}$. O fato é que universidades de menor prestigio, por motivação financeira, estão aceitando estudantes do programa sem qualquer critério e sem se preocuparem com a qualidade do ensino que será ofertado $^{26}$.

Deixam-se aqui algumas reflexões sobre o assunto: um acadêmico do Curso de Odontologia que vai ao exterior para programa de mobilidade e não consegue se inserir no seu curso de origem poderá contribuir para a qualificação da sua área de excelência? A bolsa concedida a este acadêmico com recursos públicos estará servindo ao país ou à universidade que recebeu as taxas? Não estaria o Brasil, nestes casos, apenas financiando o ensino superior em universidades estrangeiras?

\section{Diferenças de metodologia do ensino superior}

As aulas no Brasil são em grande parte centradas no professor e com caráter expositivo ${ }^{27}$ diferente dos métodos utilizados em muitas universidades onde a carga horaria é menor e o ensino é focado em pesquisa e trabalhos. Baseado nas respostas dos alunos, vimos que muitas das universidades, para as quais foram 
enviados, se utilizam de diferentes metodologias e conhecimentos pedagógicos para o ensino.

“[...] Tu não vai pra aula se quiser ficar quieto no teu canto. Tem que estudar antes, senão tu fica bem perdido". (Estudante 3).

"Aqui na nossa universidade, acho que na universidade brasileira em geral, o professor chega na aula e ele apresenta a aula. Dificilmente ele aborda de uma maneira crítica, de uma maneira que permite discussão”. (Estudante 2).

Alguns estudantes relataram o uso do modelo pedagógico conhecido por Aprendizagem Baseada em Problemas (ABP) em suas universidades de destino. Esta é uma proposta metodológica muito usado em faculdades de Medicina ao redor do mundo onde o estudante está no centro do conhecimento. O aluno é estimulado a buscar ativamente por informações para resolução dos casos que receberá, "visando o desenvolvimento do raciocínio crítico, de habilidades de comunicação e do entendimento da necessidade de aprender ao longo da vida ${ }^{28}$." Diferente das práticas pedagógicas tradicionais, esta não é meramente informativa ${ }^{29}$.

"Aqui tinha uma professora doutora em educação. Eles se preocupam muito com métodos de ensino. Por isso existe a ideia de se investir, no mínimo $50 \%$ do currículo em problem based learning, $o$ famoso PBL. É MUITO, MUUITO self learned." (Estudante 7)

"Uma das coisas que foi falada na semana de imersão é que lá o aluno tinha que estudar por conta própria. Essa era a justificativa pra gente ter menos aulas. A gente teria que que buscar o estudo em casa." (Estudante 12).

O estudo de Gomes et al. ${ }^{28}$, uma revisão de literatura sobre o ABP, mostrou que os cursos que utilizaram o método tiveram resultados melhores dos que os cursos tradicionais. $\mathrm{O}$ autor verificou que os graduandos se sentem mais preparados e foram avaliados mais positivamente por seus supervisores do que os graduandos dos cursos tradicionais, especialmente na dimensão social.

As avaliações também foram apontadas como outra diferença importante na metodologia do ensino superior.

"A avaliação não é muito objetiva. Se eles perguntam alguma coisa, tu tem que escrever tudo o que sabe sobre aquilo e não só o que eles perguntam. Essa foi uma grande dificuldade para nós [...]. (Estudante 1).

"Não tinha avaliação de múltipla escolha, eram só trabalhos escritos e isso fez eu desenvolver muito a minha escrita acadêmica. Eram trabalhos escritos em forma de artigo, em forma de revisão de literatura, de comparativo. Tudo com referência, com normas. Os trabalhos eram submetidos ao programa contra plágio. Desde o primeiro ano de faculdade é assim, eles focam nisso, é bem criteriosa essa parte de avaliação." (Estudante 3).

Chama a atenção em uma das falas a prioridade que vem sendo dada a memorização de conteúdos para as avaliações.

"Eu me desacostumei a ter que decorar". (Estudante 11).

Essa frase deveria servir como uma reflexão a professores do ensino superior, uma vez que os próprios alunos reconhecem a limitação do método em termos de efetividade na aprendizagem.

Foram percebidas também diferenças quanto aos conteúdos ministrados no curso. Essas diferenças foram percebidas especialmente pelos acadêmicos que cursaram Odontologia no 
exterior.

"[...] acabei percebendo que aqui nós não somos preparados como dentistas $e$ alunos a lidar com emergências médicas no consultório e do ponto de vista legal nós somos cobrados por isso." (Estudante 2).

No Brasil, por mais que existam clínicas integradas, o tratamento do paciente é fragmentado, com um professor para cada área atuando somente na sua especialidade. Lemos $^{30}$ fala sobre a influência da especialização que os professores exercem nas clínicas integradas, o que contribui para a lógica de fragmentação ao qual os alunos estão inseridos. Esta lógica é gerada pela resistência dos docentes especialistas em transitarem por outras especialidades além das suas ${ }^{31}$.

"A formação deles era mais generalista. Por mais que tivessem professores especialistas, na clínica integrada o professor era responsável por todas as atividades não importando a área." (Estudante 8).

O fato é que muitos profissionais que estão atuando como docentes nas escolas de ensino superior estão professores, mas não são professores ${ }^{32}$. Para exercer a tarefa de docente universitário deve-se conhecer as metodologias de ensino e as suas aplicações e não apenas transmitir conhecimentos. Fazse necessário ter competência didática.

A pouca atenção dada nas escolas de ensino superior da área da saúde para a formação de professores universitários no campo pedagógico pode ser atribuída ao fato de os critérios para contratação e progressão na carreira estarem mais ligados aos trabalhos desenvolvidos em pesquisa e em publicações cientificas do que na atuação como docente e na capacidade de ensinar ${ }^{33}$.

\section{Impacto de CsF na formação profissional}

Quando questionados sobre o impacto do $\mathrm{CsF}$ na formação profissional as opiniões foram conflitantes. Alguns estudantes relataram um impacto bastante positivo, porém outros não conseguiram visualizar benefício na formação profissional. A experiência de vida sim, foi citada como fundamental para quase todos os acadêmicos.

"Só como experiência de vida mesmo, experiência para a vida pessoal [...]. Para a vida profissional foi muito pouco, só essa decisão que eu tive de mudar a minha área, decidi não fazer mais mestrado e doutorado e voltar minha vida profissional para a clínica." (Estudante $5)$.

A ausência de impacto positivo na vida profissional pode ser atribuída as possíveis falhas na seleção dos acadêmicos e das universidades de destino, o que foi evidenciado quando foram feitas as avaliações da primeira fase do $\mathrm{CsF}^{5}$. Em muitos casos, a escolha da universidade de destino foi feita por agências internacionais, excluindo os acadêmicos dessa etapa do processo $^{7}$. Já foi discutido anteriormente o fato de os acadêmicos terem sido enviados para universidades que não permitiram a participação dos alunos no curso de Odontologia. Isto pode ser responsável pela avaliação negativa por parte dos participantes $^{2}$.

"[...] influência profissional do ciência sem fronteira...nenhuma...a nossa profissão é extremamente prática, e aqui eu não faço pesquisa, eu não entrei para essa parte acadêmica. Talvez, se eu tivesse entrado nessa área, ajudaria um pouco." (Estudante 13).

Por outro lado, foram citados impactos positivos:

"A questão de aprender a lidar com pessoas diferentes, com culturas diferentes 
foi importante. Até mesmo na profissão é importante saber lidar com isso." (Estudante 8).

"Acho que essa questão de internacionalização também é importante para que os alunos mantenham contato com o professor no exterior, para conseguir futuros trabalhos ou até para um futuro mestrado ou doutorado sanduíche. E também é preciso considerar o conhecimento que cada aluno traz para a própria universidade, seja conhecimento técnico científico ou quanto a metodologia de ensino." (Estudante 8).

\section{Contribuições do CsF para a instituição e para o país}

Um programa de internacionalização beneficiando universidades de todo o país, além de seus objetivos específicos, voltados aos alunos participantes, também pretende, mesmo que implicitamente, contribuir para as suas instituições abrirem portas e acolherem novos alunos e, principalmente, ideias. No entanto, o fato de ser apenas uma intenção e não um objetivo explícito acaba resultando em poucas contribuições como revelam as falas dos alunos.

"Eu voltei do exterior, e quando me motivava para mudar alguma coisa que não fazia nem parte do meu cotidiano, as pessoas me diziam: isso era lá no exterior, tu agora está no Brasil. Eu sempre acabava na mesma discussão. Será que porque aqui é o Brasil temos que nos conformar com as coisas que estamos vivendo? Por isso que o Brasil está na situação que está hoje." (Estudante 2)

As falas dos entrevistados revelam uma visão negativa do país, mas pode-se considerar como um impacto positivo uma vez que a crítica está surgindo. Como revelado por um dos entrevistados:

"o simples fato de estarmos tendo essas discussões [...] de tentar motivar uma visão mais crítica [...] já é importante para o desenvolvimento do país." (Estudante 2)

Em 2014, a Associação de Assessorias de Instituições de Ensino Superior Brasileiras para Assuntos Internacionais (FAUBAI) ${ }^{34}$ realizou uma conferência cujo objetivo era promover discussões sobre políticas para a educação internacional e apresentar práticas de cooperação entre instituições brasileiras e internacionais. Este movimento mostra que a criação de parcerias é considerada prioritária e uma boa oportunidade de desenvolvimento. O movimento de internacionalização surge ainda mais evidente a partir do Plano Nacional de Educação (PNE) aprovado em 2014. Em sua Meta 14 voltada ao incremento das matrículas em pós-graduação stricto sensu, uma das estratégias é a internacionalização da pesquisa ${ }^{35}$.

Alguns dos participantes da pesquisa relataram que o $\mathrm{CsF}$ pode contribuir nesse sentido enfatizando o desenvolvimento de parcerias.

"Acredito que o CsF pode contribuir nas relações entre as universidades." (Estudante 5)

Outra perspectiva sobre esta questão, é revelada por outros entrevistados que citaram que o país pode estar funcionando como "exportador" de talentos.

"O CsF pegou um dos melhores estudantes que nós tínhamos aqui, financiou ele lá. Com a inteligência que ele tinha, pensou: eu não vou ficar no Brasil, vou voltar pra lá [...] e foi isso que aconteceu. Esse o Brasil perdeu!" (Estudante 4)

Esta questão da fuga de cérebros foi abordada por Moura et $a l .{ }^{26}$ que afirmaram que 
este não deveria ser um temor, visto que as instituições, Capes e CNPq mantêm regras estritas de retorno e punição caso os alunos não regressem ao Brasil. Como a maioria dos estudantes possuem bolsas públicas, entende-se que os mesmos possuem um vínculo para retornarem. Porém, para o programa se beneficiar e evitar a perda de cientistas para outros países deve-se criar políticas que envolvam infraestrutura, laboratórios e professores atuando em nível de pós-graduação no Brasil $^{36}$, para que haja uma verdadeira circulação de cérebros ${ }^{7}$.

Entre impactos negativos e positivos, apreensões sobre a perda de novos talentos ou o alcance do desenvolvimento dos talentos a partir de oportunidades, a fala de um dos entrevistados revela que de alguma maneira o saldo final é positivo, demonstrando que podem ser percebidos impactos e contribuições positivas do programa para a comunidade e para o país.

"Eu acho que o programa forma outro tipo de cidadão. Tu é mais exigente quando tu conhece um país onde as coisas funcionam. $O$ dinheiro é aplicado bem, tu não tem medo de sair na rua, tu não tem medo de nada. Tu volta com outra exigência! Tu quer outra coisa, $e$ acho que já mudamos de atitude pra tentar fazer com que as coisas melhorem. Acho que isso, mais do que o conhecimento acadêmico, é o mais chocante." (Estudante 11).

\section{CONSIDERAÇÕES FINAIS}

A análise das falas dos participantes do Programa CsF possibilitou evidenciar aspectos relevantes na formação pessoal desses sujeitos. A experiência serviu como facilitador na definição dos rumos que iriam seguir profissionalmente. Associado ao aspecto profissional, esses estudantes também encararam uma vivência em um país estrangeiro com seus desafios inerentes ao processo. Ainda sobre o aspecto da formação profissional, de maneira mais específica, pode-se dizer que a vivência do Programa possibilitou acessar novas tecnologias, soluções, ideias reconhecidas no exterior e trazê-las para dentro do cenário da saúde no Brasil, qualificando o profissional egresso para o trabalho de uma maneira mais integrada à crescente globalização intelectual. Os estudantes trazem na bagagem novas ideias que podem inspirar outros estudantes e docentes a adotarem e colocar em prática no Brasil. Ampliam-se também as possibilidades de estabelecer as inter-relações com as universidades estrangeiras visto que muitos discentes acabam por, após o retorno, ainda manterem um vínculo com as universidades em que estudaram.

Apesar dos aspectos positivos em termos pessoais, a pesquisa também revela questões negativas em relação à organização do Programa. É evidente a necessidade de reorganização e reestruturação do Programa para que os benefícios almejados sejam alcançados de maneira mais consistente atingindo todos os participantes. Dessa forma, a internacionalização, objetivo essencial do $\mathrm{CsF}$, estará à serviço do país e da formação de seus profissionais, tendo o financiamento dos custos do ensino superior em universidade estrangeiras como meio e não fim.

\section{ABSTRACT \\ Science without Borders in professional training: perceptions of Dental students from UFSM}

This work aimed to evaluate student's perceptions about the Science without Borders program in the Dental School, Universidade Federal de Santa Maria. Qualitative research was carried out using a semi-structured interview with dentistry students who have participated in the program. The interview was recorded, 
transcribed and analyzed. From the analysis, six thematic categories were identified, Foreign Language: elements of motivation and difficulty; Personal growth: expectations fulfilled; Poor planning when the program was created; differences in higher education methodology; Science without Borders impact on professional education; and the Contributions of Science without Borders for the institution and for the country. These themes have led to the conclusion that the scholars who participated in the program have noticed the positive effects on their personal lives, but the professional development was of secondary importance.

Descriptors: Education, Dental. International Educational Exchange. Education, Higher.

\section{REFERÊNCIAS}

1. Archanjo R. Saberes sem Fronteiras: Políticas para as migrações Pós-modernas. DELTA 2016; 32(2):515-41.

2. Guskuma EM, Dullius AAS, Godinho MSC, Costa MST, Terra FS. Internacional academic mobility in nursing education: an experience report. Rev Bras Enferm. 2016; 69(5):929-33.

3. Ministério da Ciência, Tecnologia e Inovação (MCTI); Ministério da Educação (MEC); Conselho Nacional de Desenvolvimento Científico e Tecnológico (CNPq); Coordenação de Aperfeiçoamento de pessoal de Nível Superior (CAPES). Ciência sem Fronteiras [Acesso em 9 dez 2015]. Disponível em: http://www.ciencia semfronteiras.gov.br

4. Feltrin RB, Costa JOP da, Velho L. Mulheres sem fronteiras? Uma análise da participação das mulheres no Programa Ciência sem Fronteiras da Unicamp: motivações, desafios e impactos na trajetória profissional. Cad Pagu. 2016; 48: e164804.

5. Freire Junior JC. Brazil's Science Without Borders programme deserves more credit. THE (Times Higher Education). 2016.
[Acesso em 13 jul 2017]. Disponível em: https://www.timeshighereducation.com/blo g/brazils-science-without-borders-program me-deserves-more-credit.

6. Piovezan S. Graduação deverá ter peso menor na nova etapa do Ciência sem Fonteiras. G1 São Carlos e Araraquara 2015. [Acesso em 19 nov 2015]. Disponível em: http://g1.globo.com/sp/sao-carlosregiao/noticia/2015/07/graduacao-deverater-peso-menor-na-nova-etapa-do-cienciasem-fronteiras.html

7. Mcmanus C, Nobre CA. Brazilian Scientific Mobility Program - Science without Borders - Preliminary Results and Perspectives. An Acad Bras Cienc 2017; 89(1 Suppl.):773-86. [acesso em 13 jul 2017]. Disponível em: http://dx.doi.org/10.1590/0001-3765201720 $\underline{160829}$

8. Minayo MCS. O desafio do conhecimento: pesquisa qualitativa em saúde. $14^{\mathrm{a}}$ Edição. São Paulo: Hucitec; 2014.

9. Weber JJ, Horner K. Introducing Multilingualism. A social approach. London: Routledge; 2012.

10. Reeves B. Why English is not the "official language" of the United States. American Thinker. 2009 nov [Acesso em 13 jul 2017]. Disponível em: http://www.american thinker.com/articles/2009/11/why_english_i s_not the officia.html

11. Drumond Y. Inglês se aprende na escola? Revista Educação. 2013 [Acesso em 13 nov 2015]. Disponível em: http://revista educacao.uol.com.br/textos/191/ingles-seaprende-na-escola-278806-1.asp

12. Ministério da Educação (MEC). Idiomas sem Fonteiras. [Acesso em 9 dez 2015]. Disponível em: http://isf.mec.gov.br

13. Brasil. Portaria $n^{0} 1.466$, de 18 de dezembro de 2012. Institui o Programa Inglês sem Fronteiras. Diário Oficial da União $18 \mathrm{dez}$ 
2012.

14. Federação Brasileira de Bancos (FEBRABAN). $30^{\circ}$ Café com sustentabilidade. Programa Ciência sem Fronteiras. 2013 [Acesso em 29 nov 2015]. Disponível em: http://www.febraban. org.br/7Rof7SWg6qmyvwJcFwF7I0aSDf9j $\mathrm{yV} /$ sitefebraban/Caderno30Finalweb.pdf

15. Universia Brasil. Governo diminui exigência de inglês no Ciência sem Fronteiras. Universia Brasil. 2013 fev [Acesso em 20 out 2015]. Disponível em: http://noticias. universia.com.br/destaque/noticia/2013/02/ 07/1003952/governo-diminui-exigenciaingles-no-ciencia-sem-fronteiras.html

16. Archanjo R. Globalização e multilingualismo no Brasil. Competência linguística e o programa Ciência sem Fronteiras. Rev Bras Linguist Apl 2015; 15(3)621-656.

17. Brito JF de, Giloni-Lima PC, Libardoni G, Cardoso E. A internacionalização do curso de Ciências Biológicas da Unicentro: um processo em construção. In: Anais do V Encontro Nacional das Licenciaturas; 2014 dez 08-12; Natal, Brasil.

18. Dalmolin IS, Pereira ER, Silva RMCRA, Gouveia MJB, Sardinheiro JJ. Intercâmbio acadêmico cultural internacional: uma experiência de pessoal e científico. Rev Bras Enferm 2013; 66(3):442-447.

19. Oliveira MG de, Pagliuca LMF. Programa de mobilidade acadêmica internacional em enfermagem: relato de experiência. Rev Gaúcha Enferm 2012;33(1):195-8.

20. Mazza D. Intercâmbios acadêmicos internacionais: bolsas CAPES, CNPq e FAPESP. Cad Pesquisa. 2009; 39(137):52147.

21. Piovezan S. Ciência sem fonteiras é 'bom' para 53\% dos bolsistas e 'fraco' para 5\%. G1 São Carlos e Araraquara. 2015 Jul [Acesso em 9 dez. 2015]. Disponível em: http://g1.globo.com/sp/sao-carlos-regiao/ noticia/2015/07/ciencia-sem-fronteiras-ebom-para-53-dos-bolsistas-e-fraco-para5.html

22. Mückenberger E, Togashi GB, Pádua SID de, Miura IK. Gestão de processos aplicada à realização de convênios internacionais bilaterais em uma instituição de ensino superior pública brasileira. Produção 2013;23(3):637-51.

23. Lima MC, Maranhão CMS de A. O sistema de educação superior mundial: entre a internacionalização ativa e passiva. Avaliação 2009;14(3):583-610.

24. Lima MC, Maranhao CMS de A. Políticas da internacionalização do ensino superior: multiculturalismo ou semiformação? Ensaio: Aval Pol Públ Educ. 2011;19 (72):575-98.

25. Castro AA, Cabral Neto A. O ensino superior: a mobilidade estudantil como estratégia de internacionalização na América Latina. Rev Lusófona de Educação. 2012; 21: 69-96.

26. Moura C de, Barros H, Ito-Adler J, Schwartzman D. Cem mil bolsas no exterior. Rev Interesse Nac. 2012;17:25-36.

27. Cenatti MJ. Considerações sobre estratégias pedagógicas no ensino superior. Jornal da Educação. 2012 Fev [Acesso em 9 dez 2015]. Disponível em: http://www.jornalda educacao.inf.br/index.php?option=com_con tent\&task=view\&id=1605\#myGallery1picture (5)

28. Gomes R, Brino R de F, Aquilante AG, Avó $\mathrm{LR}$ da $\mathrm{S}$ de. Aprendizagem Baseada em problemas na formação médica e o currículo tradicional de Medicina: uma revisão bibliográfica. Rev Bras Educ Med. 2009; 33(3):433-440.

29. Sakai MH, Lima GZ. PBL: uma visão geral do método. Olho Mágico 1996; 2(5/6):1-4. 
30. Lemos CLS, Fonseca SG de. Saberes e práticas curriculares: um estudo de um curso superior na área da saúde. Interface 2009;13(28):57-69.

31. Cristino PS. Clínicas integradas antecipadas: limites e possibilidades. Rev ABENO. 2005;5(1):12-8.

32. Cunha MI. Docência na universidade, cultura e avaliação institucional: saberes silenciados em questão. Rev Bras Educ. 2006;11(32):258-71.

33. Costa NMSC. Docência no ensino médico: por que é tão difícil mudar? Rev Bras Educ Med. 2007;31(1):21-30.

34. Associação de Assessorias de Instituições de Ensino Superior Brasileiras para Assuntos Internacionais (FAUBAI). XXVI Encontro da FAUBAI: A Educação Superior Brasileira: Construindo Parcerias Estratégicas. 2014 Abr [Acesso em 23 nov 2015]. Disponível em: http://faubai.org.br/ conf $/ 2014 /$ ?lang=pt
35. Brasil. Lei no 13.005 de 25 de junho de 2014. Aprova o Plano Nacional de Educação PNE e dá outras providências. Diário Oficial da União 26 jun 2014.

36. Portal Brasil. Brasil precisa garantir retorno de pesquisadores que estudam no exterior. Agência Brasil 2012 Mar. [Acesso em 13 jul 2015]. Disponível em: http://www.brasil. gov.br/educacao/2012/03/brasil-precisagarantir-retorno-de-pesquisadores-queestudam-no-exterior-diz-ministro

Correspondência para:

Sílvia Ataide Pithan

e-mail: silpithan@yahoo.com.br

Alameda dos Ipês, 159/03

Nossa Senhora Medianeira

97015-30 Santa Maria, RS 